Ethos (Jurnal Penelitian dan Pengabdian Masyarakat): 122-129

\title{
PengelolaAn Penjernihan Air Sederhana Secara Mandiri Di LeVel Komunitas TEORI DAN PRAKTIK
}

\section{The Management of IndePendently Simple Water Furification In Theory And Practice COMMUNITY LeVeL}

\author{
${ }^{1}$ Ernawati Hendrakusumah, ${ }^{2}$ Hani Burhanudin, ${ }^{3}$ Odah \\ ${ }^{1,2,3}$ Program Studi Perencannaan Wilayah dan Kota, Fakultas Teknik, Universitas Islam Bandung Jalan \\ Tamansari No. 1 Bandung 40116 \\ email: ${ }^{1}$ erkoes18@gmail.com, ${ }^{2}$ hani_burhan66@yahoo.com, ${ }^{3}$ odah2004@gmail.com
}

\begin{abstract}
PKM activity is based on the phenomenon of many people who do not get access to drinking water services (SPAM) in standard quality. The PKM Objects is a community in Cikole village Lembang district, Bandung Barat regency whose predominantly work as farmers and use raw water sources to fulfil their needs and even for drinking water direct from the surface water comes from mountain spring water, without the appropriate water treatment standards. The water from the source accommodated through the water reservoirs and then distributed by gravity directly to each home with simple piping systems, without going through the process of screening and testing the water quality in advance. Regarding quality, the water requires the filtering, especially during the rainy season. Therefore through the PKM activity of "The Training of Environmental Sanitation Management: Water Treatment" hopes that the people, besides the understanding the standard criteria of water quality, are also able to do the water treatment through screening models / simple water purification that can be done independently by the community. The PKM activity has involved several related institutions, starting at the level community such as RT, RW, Kadus, water management, Cikole village officials and Lembang district, Bandung Barat regency.
\end{abstract}

Keywords: simple water purification, independently.

\begin{abstract}
Abstrak. Kegiatan PKM ini dilandasi adanya fenomena masih banyaknya masyarakat yang belum mendapatkan akses pelayanan air minum (SPAM) berbaku mutu. Objek PKM adalah masyarakat di Desa Cikole Kecamatan Lembang, Kabupaten Bandung Barat yang sebagian besar penduduknya bekerja sebagai petani dan menggunakan sumber air baku untuk memenuhi kebutuhan hidupnya dan bahkan untuk air minum dari air permukaan yang berasal dari air pegunungan, tanpa pengolahan air sesuai standar. Air dari sumbernya ditampung melalui bak penampungan air kemudian langsung didistribusikan secara gravitasi ke masing masing rumah penduduk dengan sistem perpipaan sederhana, tanpa melalui proses penyaringan dan pengujian kualitas air terlebih dahulu. Sehingga dari sisi kualitas, air tersebut, memerlukan sistem penyaringan, terutama pada saat musim penghujan. Karena itu melalui kegiatan PKM berupa "Pelatihan Pengelolaan Sanitasi Lingkungan: Penjernihan Air, diharapkan masyarakat selain paham tentang kriteria air berbaku mutu, juga mampu melakukan pengolahan air melalui model penyaringan/penjernihan air sederhana yang dapat dilakukan oleh masyarakat secara mandiri. Kegiatan PKM ini telah melibatkan beberapa institusi terkait, mulai di level komunitas RT, RW, Kadus, Pengelola Air, Aparat Desa Cikole, dan Kecamatan Lembang, Kabupaten Bandung Barat.
\end{abstract}

Kata Kunci: Penjernihan air sederhana, mandiri. 


\section{Pendahuluan}

Kesehatan merupakan modal utama untuk keberhasilan pembangunan, tanpa jiwa yang sehat tentunya proses pembangunan tersebut akan mengalami hambatan. Air bersih merupakan salah satu faktor pendukung terbentuknya masyarakat yang sehat. Pola hidup sehat yang belum tercermin di Desa Cikole terkait konsumsi air bersih yang diyakini belum memenuhi air layak konsumsi perlu diapresiasi sebagai pekerjaan rumah yang harus segera diselesaikan. Masih lemahnya tingkat pendidikan, pengetahuan dan kesadran masyarakat Desa Cikole tentang pola hidup sehat khususnya terhadap pengelolaan air akan menjadi tantangan bagi kita untuk mengubah ke arah pola hidup yang sesuai dengan kaidah kelayakan hidup sehat. Persoalannya adalah bagaimana memberikan pemahaman kepada masyarakat Desa Cikole tentang pentingnya menggunakan air bersih yang layak konsumsi.

Penyelenggaraan pelatihan Pengelolaan Sanitasi Lingkungan: Penjernihan Air di

Desa Cikole ini bertujuan menciptakan masyarakat Desa Cikole yang memiliki pengetahuan, kemauan dan kemampuan untuk menyelenggarakan pengelolaan sanitasi lingkungan (khususnya dalam hal penyediaan air bersih) sederhana secara mandiri dan berbaku mutu. Target dari kegiatan PKM ini adalah agar masyarakat Desa Cikole memahami substansi kriteria air baku mutu dan memahami teknik penyaringan air.

Manfaat kegiatan PKM adalah: Masyarakat Desa Cikole memiliki pengetahuan tentang kriteria air baku mutu dan panduan tentang teknik penyaringan air. Luaran kegiatan PKM dokumen kriteria air baku mutu dan teknik penyaringan air

Kegiatan PKM ini diharapkan bermanfaat bagi khalayak sasaran khususnya dan bagi masyaraat umum di Desa Cikole dan sekitarnya dalam hal sistem penyediaan air "minum" (PAM) sederhana secara mandiri, termasuk aparat dusun dan Desa Cikole. Ke depan diharapkan dengan pengetahuan hasil PKM ini masyarakat dusun dan Desa Cikole secara kelembagaan (desa) terinspirasi untuk mengembangkan SPAM dengan kualitas air yang memenuhi syarat kesehatan.

\section{Metodologi Pelaksanaan}

Berdasarkan kondisi lapangan, terdapat beberapa model sistem penyaringan air bersih, yaitu:

[1]. Dilakukan sistem penyaringan di sumber mata air, kemudian didistribusikan ke masingmasing bak pembagi, lalu kemudian didistribusikan ke masingmasing rumah (sambungan rumah);

[2]. Sistem penyaringan dilakukan pada masingmasing bak pembagi sebelum didistribusikan ke masingmasing rumah; dan

[3]. Sistem penyaringan dilakukan pada bak di masingmasing rumah pengguna air.

Model penyaringan air tersebut dapat dilihat pada gambar 1 dan 2 berikut ini. 

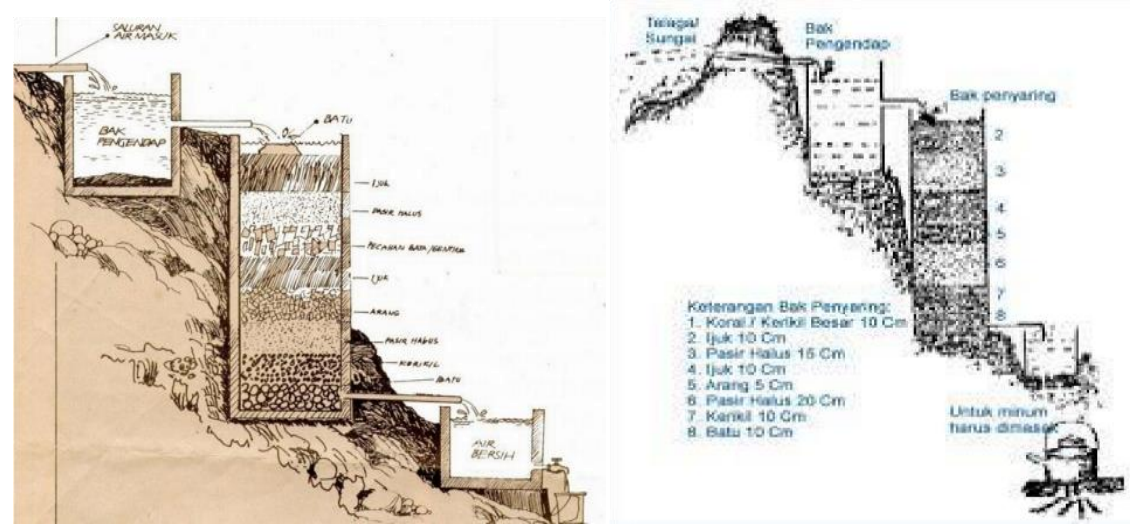

Gambar 1. Sistem Penjernihan Air Mulai dari Sumber Air sampai dengan Sambungan Rumah

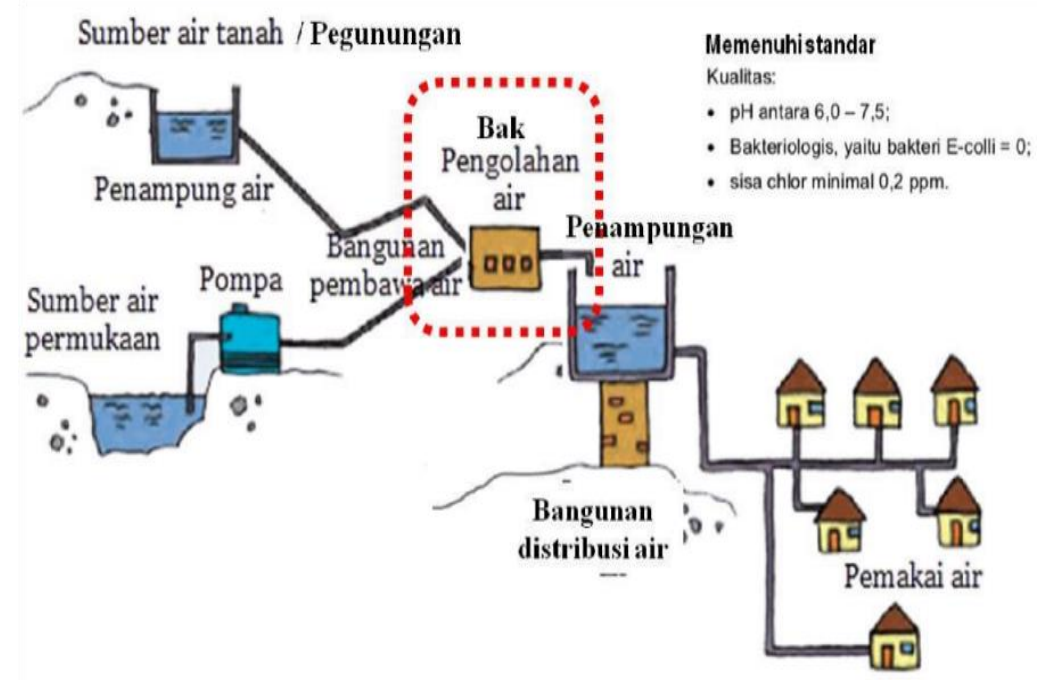

Gambar 2. Sistem Penjernihan Air Mulai dari Sumber Air sampai dengan Sambungan Rumah

\section{Hasil dan Pembahasan}

\section{Langkah-langkah/Tahapan Praktik Penjernihan Air}

Hal-hal yang perlu dilakukan sebelum memulai teknik penjernihan air adalah sebagai berikut:

[1]. Identifikasi asalusul dan kondisi lingkungan mata air permukaan yang akan digunakan sebagai sumber air utama;
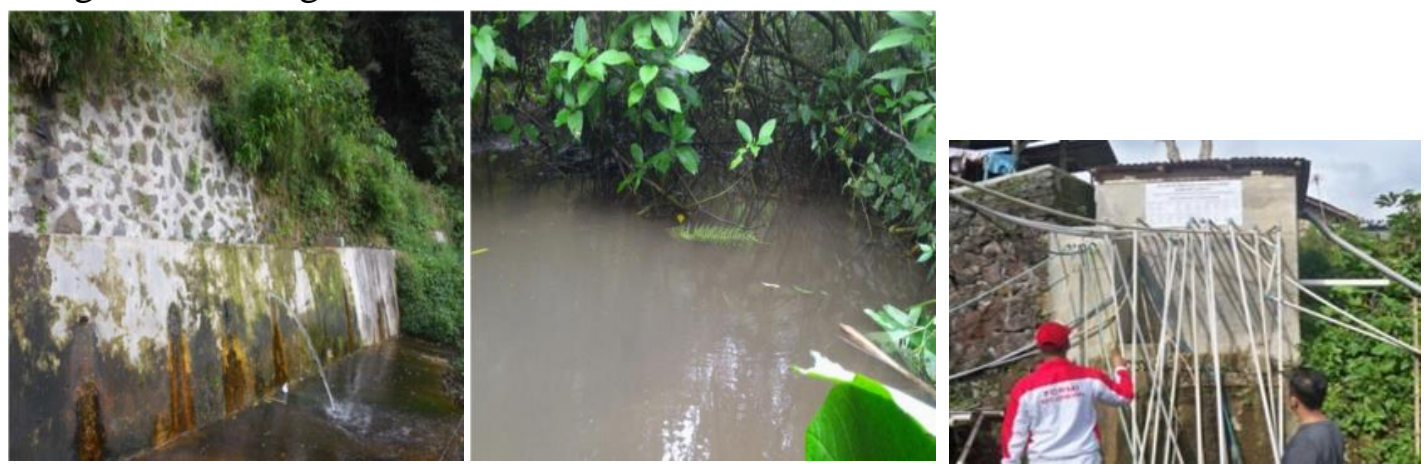

Gambar 3. Contoh Sumber Mata Air Permukaan, Bak Pembagi, dan slang distribusi 
Tabel 1. Nama Mata Air di Desa Cikole dan Wilayah Pelayanannya

\begin{tabular}{|c|c|c|c|}
\hline No & Mata Air & Wilayah Pelayanan & Permasalahan \\
\hline 1 & Citamiang * & RW 2, RW 5, RW15 & \multirow{4}{*}{ Masalah sampah dan air bersih } \\
\hline 2 & RBPK & RW 1, RW 3, RW 6, BRIMOB & \\
\hline 3 & Paresin & RW 3, RW6, RW7 & \\
\hline 4 & Susukan Haji Mansur & RW 7, Bela Negara & \\
\hline 5 & Amblongan & RW 8, RW 9, RW 10, RW 11, RW 12 & \multirow{6}{*}{$\begin{array}{l}\text { Masalah sampah, air bersih, } \\
\text { kotoran sapi }\end{array}$} \\
\hline 6 & Cikole Gede & RW 7 & \\
\hline 7 & Cikahuripan & RW 11 & \\
\hline 8 & Mesin & RW 13, RW 14 & \\
\hline 9 & Cipaswara * & RW 14 & \\
\hline 10 & Ciibu* & RW 14 & \\
\hline
\end{tabular}

Sumber : Kantor Desa Cikole, 24052016

Keterangan: *mata air yang berdekatan dengan permukiman

Dari 10 mata air tersebut, Mata Air Citamiang memiliki debit air paling besar. Sebagian besar mata air berlokasi di kawasan hutan, dan ada juga yang keberadaannya berdekatan dengan kawasan permukiman seperti MA. Citamiang, MA. Cipaswara dan MA Ciibu.

[2]. Lakukan pengujian laboratorium kualitas air permukaan yang dimaksud, agar diketahui kondisi airnya (baik secara fisik maupun kimiawi), agar mudah kita menentukan sistem penyeringan/penjernihan mana yang tepat digunakan.

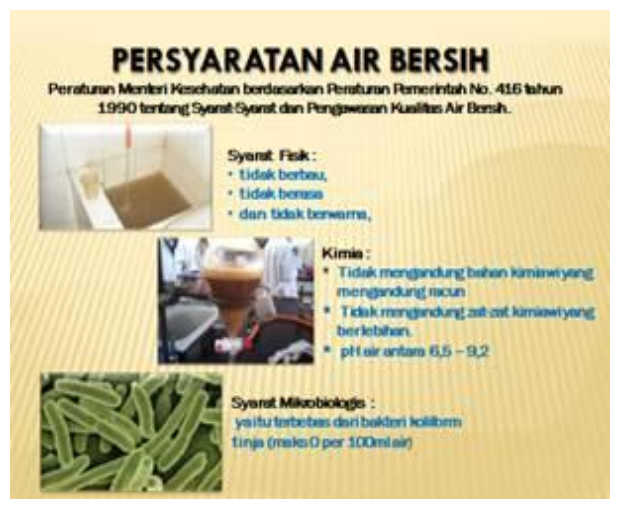

\begin{tabular}{|c|c|c|c|c|}
\hline No & $\begin{array}{l}\text { PARAMEIER } \\
\text { Parameter }\end{array}$ & $\frac{\text { SAIUAN }}{\text { Unit }}$ & $\begin{array}{l}\text { BAKU Mutu } \\
\text { Specification }\end{array}$ & $\begin{array}{l}\text { METODA ACUAN } \\
\text { Method of Reterence }\end{array}$ \\
\hline & FiSIKA & & & \\
\hline 1 & Bav. & . & lidak Berbau & Organoleptik \\
\hline 2 & Podatan ferilarut Iotal (TDS] & $\mathrm{mg} / \mathrm{h}$ & 1500 & SN1 06-6989.27-2005 \\
\hline 3 & Kekoruhan & NiU & 25 & SN1 $06-6989.25-2005$ \\
\hline 4 & Wano & PACO & 50 & SNI $06-6989.24 .2005$ \\
\hline & KIMIA & & & \\
\hline 1 & Besi $\left(\mathrm{Fe}_{\mathrm{e}}^{*} \mathrm{~s}^{\circ}\right.$ & $\mathrm{mg} / \mathrm{h}$ & 1.0 & USEPA Methode No 200.7 \\
\hline 2 & Kesodahon Total $\left(\mathrm{CoCO}_{2}\right)$ & $\mathrm{mg} / \mathrm{h}$ & 500 & SN106-6989.12-2004 \\
\hline 3 & Klotida [Cl] & $\mathrm{mg} / \mathrm{h}$ & 600 & 50116989.19 .2009 \\
\hline 4 & Mangan (Mn)." & $\mathrm{mgh}$ & 0.5 & USEPA Methode No 2007 \\
\hline 5 & Netrot $(\mathrm{NO}, \mathrm{N})$ & $\mathrm{mg} / \mathrm{h}$ & 10 & SN1 $6989.79: 2011$ \\
\hline 6 & Nitrit $[\mathrm{NO}, \mathrm{N}$ ) & $\mathrm{mg} / \mathrm{h}$ & 1 & SN1 06.6999.9.2004 \\
\hline$?$ & $\mathrm{gH}$ & $\cdot$ & $6.5 \cdot 9.0$ & SN1 $06-6989.11-2004$ \\
\hline 8 & Sulfot $\left(50,2^{2}\right)$ & $m g / 2$ & 400 & SN16 6989.20:2009 \\
\hline 9 & Nali Permanganat [KMnO, & $\mathrm{mg} / \mathrm{h}$ & 10 & 5NA OS- $6967.22-2004$ \\
\hline 10 & Aluminumm $|\mathrm{A}|$ & $\mathrm{mg} / \mathrm{h}$ & - & USEPA Mothode No 200.7 \\
\hline & MIKROBIOLOGI & & & \\
\hline 1 & Collorm & $\mathrm{m} \mathrm{m} / 100 \mathrm{~mL}$ & so & SM 9221 \& ** \\
\hline
\end{tabular}

Gambar 4. Persyaratan Air Bersih

Keterangan:

a. Air bersih adalah air yang digunakan untuk keperluan seharihari yang kualitasnya memenuhi syarat kesehatan dan dapat diminum apabila telah dimasak;

b. Logam berat merupakan logam terlarut $(*)$

c. Standar methode: Edisi ke 22 Tahun $2012\left({ }^{* *}\right)$ 
[3]. Pahami secara teori terkait dengan kriteria standar mutu kualitas air layak pakai (lihat tabel di atas) dan modelmodel sistem penjernihan/penyaringan air sederhana;
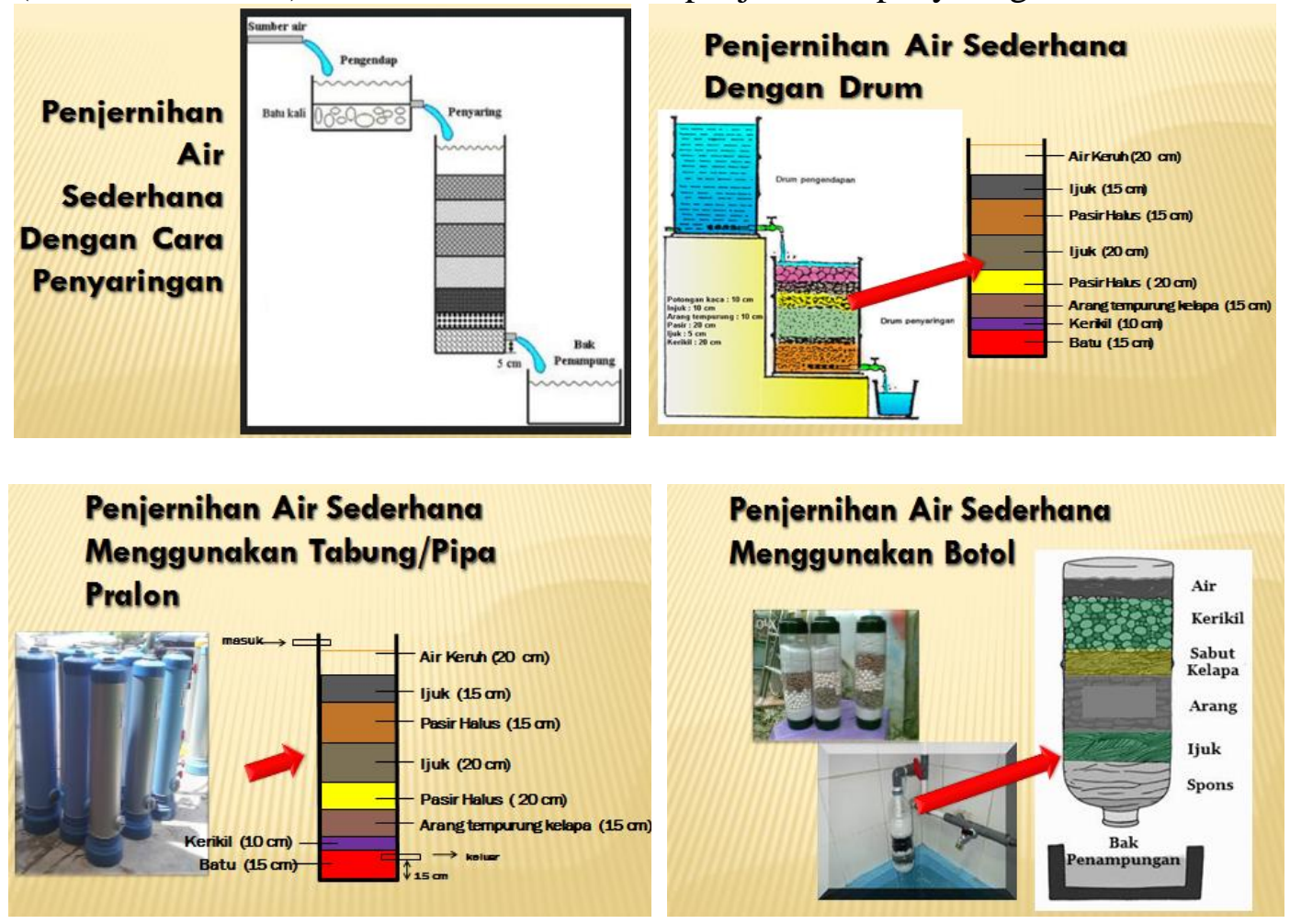

Gambar 5. Model-model penjernihan/Penyimpangan air

Siapkan bahan-bahan dan alat-alat istem penjernihan air sesuai dengan kualitas kondisi air yang ada di lapangan

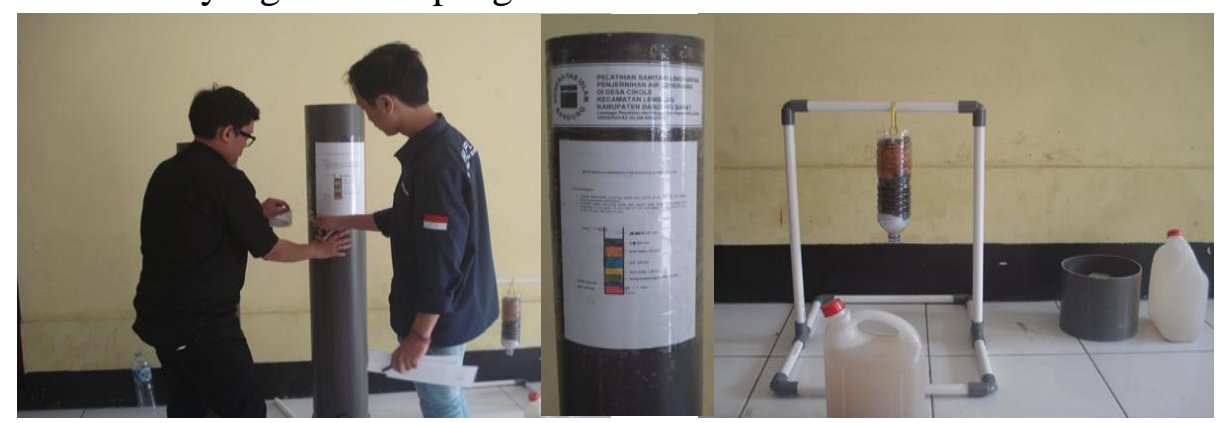

Model penjernihan air sederhana dari pipa paralon dan botol "aqua" paralon 


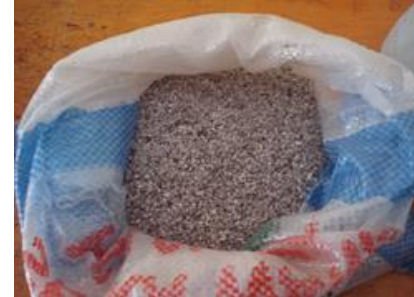

Pasir Kwarsa

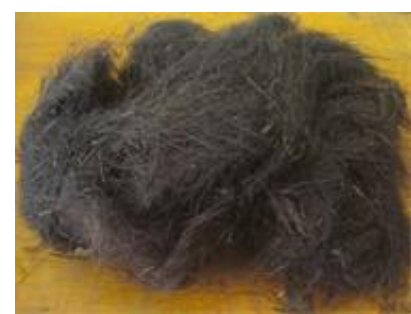

ljuk

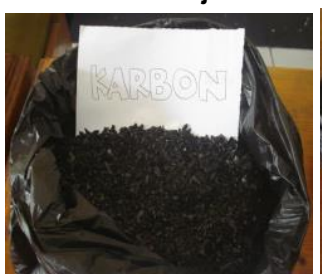

Karbon

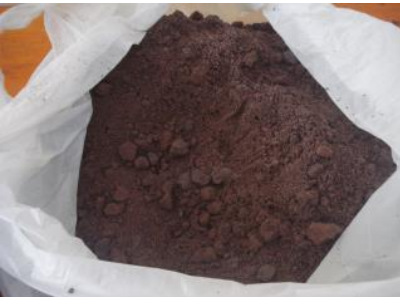

Pasir Beton I/II

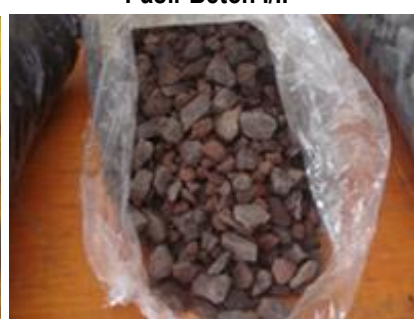

Batu Kerikil/Koral

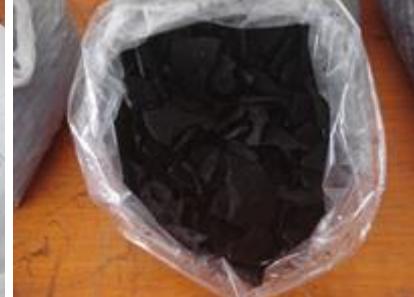

Arang Batok

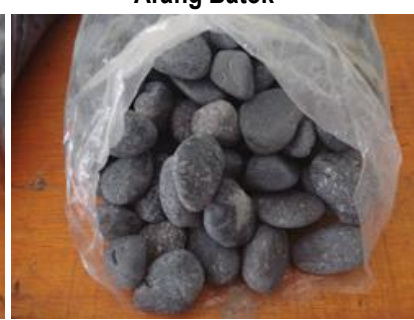

Batu bulat

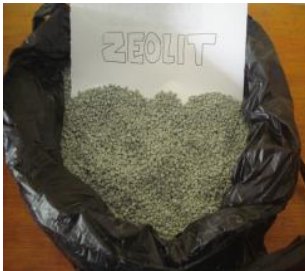

Batu Zeolit

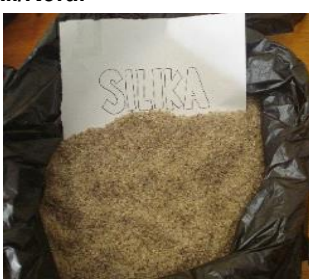

Batu S\Silika

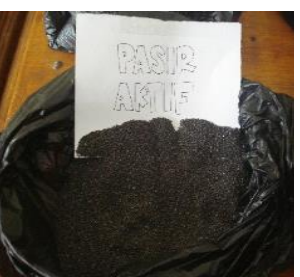

Pasir aktif

(bahan-bahan ini diperlukan apabila kondidi air kotor dan mengandung unsur kimia, bakteri)
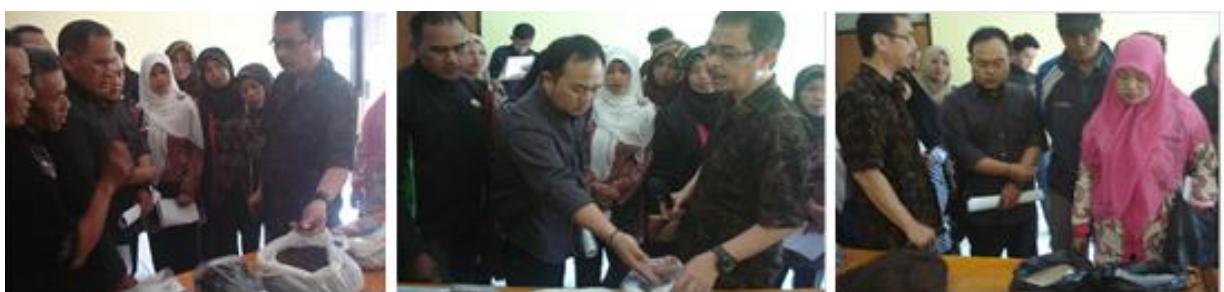

Gambar 6. Bahanbahan untuk media penyaringan air

Pilih model penyaringan yang paling tepat, sesuai dengan kebutuhan. Misal: apabila hanya mau menghilangkan kekeruhan air langsung dari bak distribusi, dapat dipilih model filter dari pralon besar; atau apabila sistem penyaringan akan dilakukan di bak kamar mandi, maka dapat dipilih model tabung penyaringan yang lebih sederhana dari "botol plastik aqua". Jenis, susunan, dan ukuran tebal media saringan, disesuaikan dengan gamar standar dan dipadatkan sesuai kebutuhan.
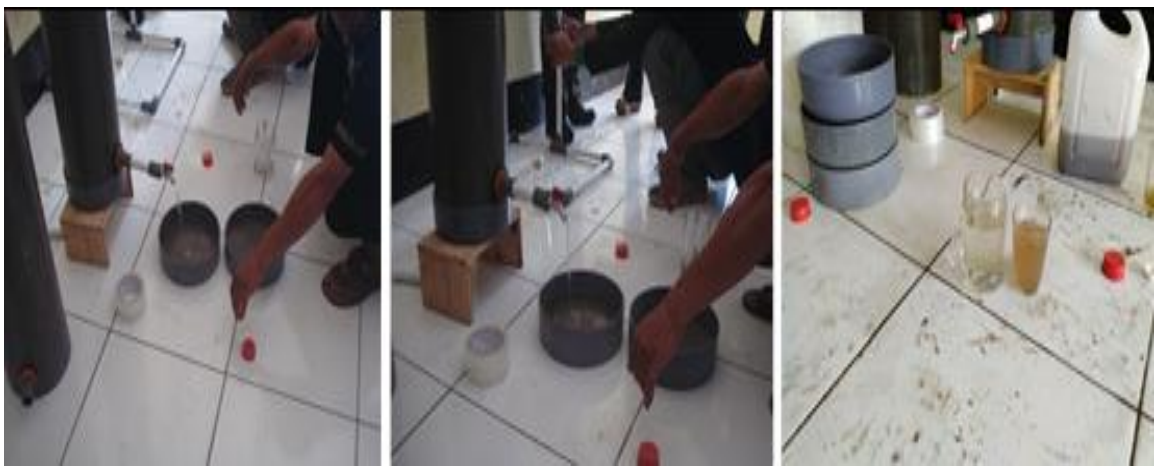

Gambar 7. Hasil Penyaringan 
Hasil penyaringan dapat menurunkan kadar kekeruhan air sampai $>80 \%$, sebagaimana diperlihatkan pada foto di atas.

\section{Evaluasi}

Pelaksanaan kegiatan PKM "Pelatihan Penjernihan Air di Cikole mendapat apreasiasi posistif dari warga. Ini diperlihatkan dengan kehadiran paserta dari awal sampai akhir selesai pelatihan. Untuk melihat sejauh mana materi hasil PKM diterima, dimanfaatkan, serta ditindaklanjuti oleh masyarakat, dilakukan pemantauan (monitoring dan evaluasi) terhadap sikap dan tindak lanjut masyarakat terhadap hasil kegiatan PKM. Kriteria dan indikator keberhasilan dari pelaksanaan PKM ditunjukkan oleh:

[1]. Adanya pemahaman masyarakat terhadap teori sistem penyaringan air;

[2]. Terjadi peningkatan kualitas (mutu) air sesuai ketentuan baku mutu air layak konsumsi;

[3]. Terjadi replikasi praktik pembuatan sistem penyaringan air pada bakbak penampungan air lainnya yang ada di Desa Cikole.

Untuk mengetahui pemahaman masyarakat terhadap pentingnya air memenuhi baku mutu air layak konsumsi dan bagaimana tata cara pembuatan sistem penyaringan air yang dapat menghasilkan ketentuan baku mutu air, evaluasi dilakukan melalui kuesioner dan lembar penilaian. Kemudian untuk mengetahui adanya peningkatan kualitas air sesuai dengan baku mutu air layak konsumsi, dilakukan melalui uji laboratorium air; dan untuk mengetahui ada/tidaknya outcome sebagai dampak positif dari hasil kegiatan PKM ini, ditunjukkan oleh minimal adanya minat masyarakat untuk mereplikasi sistem penyaringan air percontohan.

\section{Kesimpulan}

Kegiatan PKM Pelatihan Penjernihan Air telah menambah pengetahuan kepada peserta pelatihan sehingga mampu memahami dan menyadari sepenuhnya bahwa untuk memanfaatkan sumber air permukaan, sebaiknya perlu dilakukan uji laboratorium terkait dengan kualitas air layak konsumsi. Terdapat ragam model sistem penjernihan air, tergantung pada kondisi geografis (alam), jumlah sambungan rumah dan jarak jangkau layanan, sumberdaya manusia, dan faktor ketersediaan biaya. Namun demikian setiap keluarga dapat melakukan sistem penyaringan/penjernihan air sederhana secara mandiri. Beberapa peserta (hasil kuesioner) mengharapkan ke depan ada rencana pengembangan/pembangunan sistem penyediaan air bersih layak minum yang dapat difasilitasi oleh pemerintah baik pusat maupun daerah.

Model penyaringan yang dilatihkan lebih bersifat individual. Supaya lebih efisien dan dalam rangka pemenuhan standar pelayanan minimum kepada masyarakat dalam akses terhadap air baku (standard), de depan perlu dikembangkan pengembangan sistem penyediaan air minum (SPAM) secara komunal. Sistem jaringan instalasi distribusi air dari bakbak penampungan yang ada saat ini secara visual kurang tertata dengan baik dan cukup mengganggu pemandangan. Karena itu ke depan perlu dibangun instalasi distribusi air komunal yang memenuhi standar teknis SPAM dengan sistem distribusi perpipaan yang lebih heigenis dan estetis. Agar hasil pelatihan dapat disebarluaskan oleh padara kade desa, perlu dilakukan pembinaan kader secara berkelanjutan.

\section{Ucapan Terima Kasih}




\section{Daftar pustaka}

Da Silva, F. O. E., T. Heikkila, et al. (2010). Developing Sustainable and Replicable Water Supply Systems in Rural Communities in Brazil. The International Journal of Water Resources Development. 629(4), 622635

Nugraheni, P. \& Argo, T. (2011). Identifikasi Upaya Keberlanjutan Pengelolaan Air Minum Perdesaan di Kabupaten Tulungagung. Jurnal Perencanaan Wilayah dan Kota B SAPPK V3N1

Tadesse, A., T. Bosona, et al. (2013). Rural Water Supply Management and Sustainability: The Case of Adama Area, Ethiopia. Journal of Water Resource and Protection 5(2), 208221.

Buku Lembaga/Instansi sebagai Penerbit

Bappenas (2003). Kebijakan Nasional Pembangunan Air Minum dan Penyehatan Lingkungan Berbasis Masyarakat. Jakarta: Bappenas.

Media Elektronik

Anonim. (2004). Estimated Use of Water in the United States in 2000, (http://pubs.usgs. gov/circ/ 2004/circ1268/htdocs/figure11.html, diakses 18 Desember 2015).

Masduqi, A. \&Wahyono, H, dkk. (2013). Teknologi Penyediaan Air Bersih Perdesaan:

Studi Kasusdi Kabupaten Mojokerto. FTSP ITS, (http://personal.its.ac.id/files/ pub/2103 diakses18 Desember 2015).

Peraturan dan PerundangUndangan

Undangundang Nomor 26 Tahun 2007 tentang Penataan Ruang

Undangundang Nomor 23 Tahun 2014 tentang Pemerintahan Daerah.

Peraturan Pemerintah Nomor 16 Tahun 2005 tentang Pengembangan SPAM

PERMENPU 14/PRT/M/2010 tentang StandarPelayanan Minimal

Undangundang No. 23/1997 tentang Pengelolaan Lingkungan Hidup (Pencemaran Lingkungan Hidup).

Undangundang Nomor 36/2009 tentang Kesehatan, Bab XI Kesehatan Lingkungan

Perraturan Pemerintah No. 82 Tahun 2001 tentang Pengelolaan Kualitas Air dan Pengendalian Pencemaran air.

Permenkes 492/menkes/IV/2010 tentang Persyaratan Kualitas Air Minum

Peraturan Pemerintah Nomor 16 Tahun 2005 tentang Pengembangan Sistem Penyediaan Air Minum (SPAM).

SNI 1967732002 tentang Spesifikasi Unit Paket Instalasi Pengolahan Air.

Mata Kuliah Stream Perencanaan Wilayah dan Desa (2013). Laporan Rencana Tata Ruang Desa (Village Planning) Cikole, Kecamatan Lembang Kabupaten Bandung Barat.

Profil Desa Cikole 2014. Desa Cikole, Kecamatan Lembang, Kabupaten Bandung Barat, 2014. 